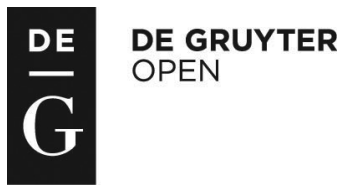

\title{
EFFECT OF LIGHT EMITTING DIODES WITH DIFFERENT COLOR TEMPERATURES ON IMMUNE RESPONSES AND GROWTH PERFORMANCE OF MALE BROILER
}

\author{
Hossein Sharideh", Mojtaba Zaghari \\ Department of Animal Science, University of Tehran, Karaj 31587-11167, Iran \\ •Corresponding author: hosseinsharideh@ut.ac.ir
}

\begin{abstract}
The aim of the present study was to evaluate the effects of the different color temperatures (Kelvin; K) of the light emitting diodes (LEDs) on broiler chicken health and growth performance compared to incandescent (ICD) light bulbs. Three hundred and sixty one-day-old Ross 308 male chicks were tested for 42 days. The chicks were randomly distributed into three treatment groups [neutral-white $(4,286 \mathrm{~K})$, warm-white $(2,990 \mathrm{~K})$, and ICD $(2,790 \mathrm{~K})$ light bulbs] of 120 chicks/treatment with six replicates each by adopting complete randomized design. The diets were similar for all treatment groups. The live body weight and feed intake were recorded weekly and feed conversion ratio (FCR) was calculated (weekly and whole period). Indices of humoral immunity [antisheep red blood cell (SRBC) titer, IgG, and IgM at 26 and 34 days of age], Newcastle disease (ND) virus and avian influenza (AI) virus antibody at 40 days of age, cell-mediated immunity [cutaneous basophilic hyper-sensitivity (CBH) response at 41 days of age)] as well as total and differential leukocyte numbers at 42 days of age) were measured. Effects of different color temperatures of the LEDs and ICD light bulbs on body weight, feed consumption, and FCR were not statistically significant $(\mathrm{P}>\mathbf{0 . 0 5})$. Also, the effect of color temperatures of light on secondary titers of SRBC, AI antibody response, $\mathrm{CBH}$ response, the total number of leukocytes and percentage of lymphocytes were not significant. However, the different color temperatures of LEDs have a significant effect on primary SRBC and ND antibody titers $(\mathrm{P} \leq 0.05)$. The highest primary $S R B C(\mathrm{P} \leq 0.05)$ and ND $(\mathrm{P} \leq 0.05)$ antibody titers were observed in warm-white light. It was concluded that based on the 3 color temperatures examined, it seems that the most suitable to provide the optimum level of immunity and energy-saving in commercial broiler houses is warm-white light.
\end{abstract}

Key words: artificial light, broiler, different color temperatures, immune responses, feed conversion ratio

Light is an important environmental factor to influence many factors such as the behavior (Skoglund and Palmer, 1962), activity (Levenick and Leighton, 1988), reproductive characteristics (Bobadilla-Mendez et al., 2016), growth performance (Rozenboim et al., 2004) and immunity of birds (Xie et al., 2011; Seo et al., 2015), 
and it is widely used in the poultry industry. Presently in Iran, the light source used in broiler houses is mainly incandescent (ICD) light bulbs. With the expected continued increase in energy prices, an interest has grown to use less energy-consuming light sources. Light-emitting diodes (LED) are much more energy efficient and provide sufficient brightness (Hassan et al., 2014). Thus, most of the poultry producers have replaced ICD lamps with LEDs. Moreover, LEDs are potentially beneficial to the poultry industries due to long life span, moisture resistance, and narrow spectrum (Olanrewaju et al., 2015). The first LEDs developed were monochromatic; they had a very narrow spectrum so that the resulting color appeared different from white $(500 \mathrm{nM})$. Recently, LEDs emitting white light with a range of color temperatures (a way to describe the light appearance) have been developed. Color temperature is measured in degrees of kelvin $(\mathrm{K})$ on a scale from 1,000 [very warm (yellowish)] to 10,000 [very cool (bluish)]. It depends on the spectral characteristics, for example, the power emitted from the different wavelengths, but it differs in white light which includes all the wavelengths of the visible spectrum (Riber, 2015). Furthermore, color temperature is thus an indication of the color appearance of white light, with warmer colors having lower temperatures (Riber, 2015). In this study, we used two color temperatures: 2,990 and 4,286 K as warm-white and neutral-white, respectively.

Recent study on broilers showed that monochromatic blue and green light improved welfare and performance. Cao et al. (2008) suggested that blue and green monochromatic lights were more effective to stimulate testosterone secretion and myofiber growth of broiler chickens that led to increased body growth compared to white and red lights. Also, several studies on broilers showed that blue and green have a positive effect on growth performance (Rozenboim et al., 2004), bird welfare (Bessei, 2006), and cellular and humoral immune responses (Xie et al., 2008). Studies on broiler chickens showed that different color lights had an alleviating effect on stress responses in broilers (Xie et al., 2008; Huth and Archer, 2015).

Most research has been done on monochromatic light, whereas researches into a white light with different color temperatures are rare. So, the aim of the present study was to determine the effects of the different color temperatures of the LEDs (neutral-white and warm-white) compared to the ICD light bulbs in male broiler chickens on growth performance, immune responses and welfare indices.

\section{Material and methods}

\section{Light treatments and management}

A total of 360 one-day-old male Ross 308 broiler chicks were used to evaluate the effects of the different color temperatures of the LEDs on broiler chicken health and performance compared to the ICD light bulbs. This experiment involved three treatments: neutral-white (4,286 K), warm-white (2,990 K; both from Ava Noor Gostaran Alborz Co, Karaj, Iran), and ICD (2,790 K) light bulb. A comparison of spectra between these bulbs can be seen in Figure 1. Each treatment consisted of 6 pens 
$\left(1.2 \times 2 \mathrm{~m} ; 0.12 \mathrm{~m}^{2} /\right.$ bird $)$ containing 20 male broiler chicks each in a light tight room equipped with one of the light sources. The room temperature of the three treatments was set to $33^{\circ} \mathrm{C}$ during the first $3 \mathrm{~d}$ and then gradually lowered to $20^{\circ} \mathrm{C}$ on $\mathrm{d} 28$, where it remained. Each pen was outfitted with one plastic pan feeder, one bell drinker, and covered by $5 \mathrm{~cm}$ wood shaving material. The birds received mash diet from one to $42 \mathrm{~d}$ of age and had free access to water and feed. The diets (as recommended by Broiler Management Manual for Ross 308) were similar for all treatment groups in 3-phase feeding program (starter: 1 to $14 \mathrm{~d}$; grower: 15 to $28 \mathrm{~d}$; finisher: 29 to $42 \mathrm{~d}$ ). At one day of age, the birds were given $24 \mathrm{~h}$ light at 50 Gallilux of light (using a light meter; Hato Galli-Luxmeter, Handelsstraat 31, 6135 KK Sittard, The Netherlands), and then for the rest of the trial were kept under a 23L:1D photoperiod at 50 Gallilux of light.

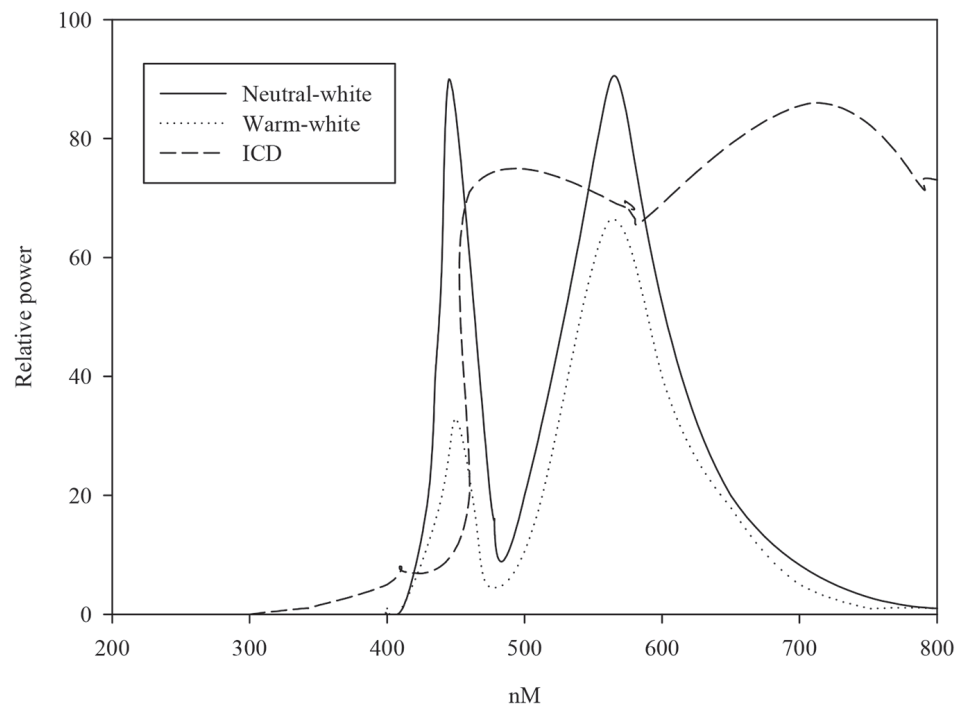

Figure 1. Comparison of spectrum readings of the 3 different lighting sources: neutral-white (4,286 K), warm-white $(2,990 \mathrm{~K})$, and incandescent (ICD; 2,790 K) light bulbs used in this study

\section{Broiler chicken performance}

Feed intake and body weight were recorded weekly to calculate feed conversion ratio (FCR) as $\mathrm{g}$ feed intake/g weight gain. Feed conversion ratio was calculated by dividing the total feed intake per pen by the total body weight gain per pen and was corrected for mortality and day 0 weight. Broiler chickens were checked daily for mortality. Percentage of mortality was calculated as the number of birds that died throughout the study compared to the initial number placed in the pen.

\section{Anti-SRBC antibody assay}

A phosphate-buffered (PBS; $\mathrm{pH}=7.5)$ suspension of SRBC (5\%) was injected (one $\mathrm{mL}$ ) into the breast muscle of 12 chicks per treatment at $26 \mathrm{~d}$ of age. The same birds then received a booster injection at $34 \mathrm{~d}$ of age. Seven days after each injec- 
tion, $2 \mathrm{ml}$ of blood was drawn from the brachial vein of the birds into heparinized tubes. The blood samples were centrifuged for $12 \mathrm{~min}\left(1800 \times \mathrm{g}\right.$ at $\left.18^{\circ} \mathrm{C}\right)$ and plasma from each sample decanted and kept at $-20^{\circ} \mathrm{C}$ for later analysis. Total anti-SRBC antibody, IgG and IgM titers were assayed using methods described by Van Der Zijpp and Leenstra (1980). Briefly, serum was pipetted into micro-centrifuge tubes and inactivated by heat in a $56^{\circ} \mathrm{C}$ water bath for $30 \mathrm{~min}$. To assess total antibodies, $50 \mu \mathrm{L}$ of PBS and $50 \mu \mathrm{L}$ of serum were placed in the first row of wells in a 96-well V-bottom microtitration plate (Corning Glass, Corning, NY, USA), and the solution was incubated for $30 \mathrm{~min}$ at $37^{\circ} \mathrm{C}$. Then, $50 \mu \mathrm{L}$ of PBS was added to the remaining wells to make a 2-fold serial dilution for each sample on successive rows. Finally, $50 \mu \mathrm{L}$ of $5 \%$ SRBC suspension was added to each well. Total antibody titers were then read after $30 \mathrm{~min}$ of incubation at $37^{\circ} \mathrm{C}$. The titers were expressed as $\log _{2}$ of the reciprocal of the highest dilution giving visible agglutination. The IgG ME-resistant (MER) and IgM ME-sensitive (MES) antibody titers were assessed using the same procedure as for total titers except that $50 \mu \mathrm{L}$ of 0.02 molar mercaptoethanol in PBS was used instead of PBS alone. The difference between total and MER titers was considered as the MES titer.

\section{CBH response}

The cutaneous basophil hyper-sensitivity $(\mathrm{CBH})$ response to phytohemagglutinin-M (PHA-M; Gibco, Grand Island, NY, USA) was used to assess the in vivo cellmediated immune response. At $41 \mathrm{~d}$ of age, 12 birds per treatment received $0.1 \mathrm{~mL}$ of PHA-M intradermally between the second and third digits of the right foot. The left foot was injected with $0.1 \mathrm{~mL}$ of PBS $(\mathrm{pH}=7.5)$ as control. Toe web thickness was measured just prior to injection and $24 \mathrm{~h}$ post-injection with a pressure sensitive caliper, and the response was evaluated as follows: [(thickness of right toe web postinjection - thickness of right toe web preinjection) - (thickness of left toe web postinjection - thickness of left toe web preinjection)] (Akhlaghi et al., 2013).

\section{Immunization against Newcastle disease virus and avian influenza virus}

All the birds were subcutaneously vaccinated against Newcastle disease (ND) virus and avian influenza (AI) virus at $9 \mathrm{~d}$ of age. To evaluate the antibody response to ND and AI, blood samples from 8 birds at $42 \mathrm{~d}$ of age were collected for subjecting their sera to Hemagglutination Inhibition (HI) tests to determine the antibody response titers of ND and AI vaccines.

\section{Total and differential leukocyte enumeration}

At $42 \mathrm{~d}$ of age, blood samples $(0.5 \mathrm{~mL})$ were collected into EDTA-coated tubes from the brachial vein ( 8 birds/treatment) to enumerate the total leukocytes, using Natt-Herrick's solution and a hemacytometer (Akhlaghi et al., 2013). The percentages of lymphocytes, monocytes, heterophils, eosinophils, basophils, and heterophil to lymphocyte (H:L) ratio were determined, using blood smears with Wright's staining procedure and counting 100 cells per slide (Zhandi et al., 2016). 


\section{Statistical analysis}

The chicks were randomly distributed into three treatment groups of 20 chicks/ treatment with six replicates each by adopting complete randomized design. All data were checked for normal distribution by UNIVARIATE procedure and Shapiro-Wilk test. The data were analyzed by the general linear model (GLM) procedure of statistical analysis system (SAS) 9.1 (SAS Institute, 2002). The results were represented as LS mean \pm SEM where they were compared by the Tukey's test (honestly significant difference; HSD) at $\mathrm{P} \leq 0.05$. The GLM model used in the present study was as follows:

$$
Y i=\mu+T_{i}+e_{i}
$$

where:

$Y_{i}$ is the observed dependent variables (including growth performance and immune responses data),

$\mu$ is mean of population,

$T_{i}$ is the effect of the treatment ( $\mathrm{i}=1,2$ and 3$)$,

$e_{i}$ is random residual error.

\section{Results}

The influence of LEDs and ICD light bulbs on body weight, feed consumption, FCR and mortality rate during this study ( 1 to $42 \mathrm{~d}$ of age) are presented in Table 1. The effects of the different color temperatures of the LEDs and ICD light bulbs on body weight, feed consumption, FCR and mortality rate were not statistically significant ( $\mathrm{P}>0.05$; Table 1$)$. However, marginally the body weight, and feed consumption were highest (at 4 and 5\%, respectively), and FCR was lowest (at 1.65\%) in birds reared under warm-white light compared to other treatments.

Table 1. Effect of different color temperatures (kelvin) compared to incandescent (ICD) light bulbs on male broiler chicken performance

\begin{tabular}{|c|c|c|c|c|c|}
\hline \multirow{2}{*}{ Item } & \multirow{2}{*}{ ICD } & \multicolumn{2}{|c|}{ Treatment } & \multirow{2}{*}{ SEM } & \multirow{2}{*}{ P-value } \\
\hline & & warm-white & neutral-white & & \\
\hline 1 & 2 & 3 & 4 & 5 & 6 \\
\hline \multicolumn{6}{|l|}{$7 \mathrm{~d}$} \\
\hline BW (g) & 152.64 & 153.52 & 152.48 & 2.86 & 0.96 \\
\hline BW gain (g/bird/d) & 21.80 & 21.93 & 21.87 & 0.46 & 0.96 \\
\hline Feed intake (g/bird/d) & 22.50 & 23.00 & 22.40 & 0.29 & 0.50 \\
\hline FCR (g feed/g BW) & 1.03 & 1.05 & 1.03 & 0.01 & 0.47 \\
\hline Mortality (\%) & 1.60 & 0.00 & 0.83 & 0.77 & 0.34 \\
\hline \multicolumn{6}{|l|}{$14 \mathrm{~d}$} \\
\hline BW (g) & 381.10 & 402.00 & 396.70 & 9.00 & 0.26 \\
\hline BW gain (g/bird/d) & 32.45 & 35.49 & 34.88 & 1.12 & 0.16 \\
\hline
\end{tabular}


Table 1 - contd.

\begin{tabular}{|c|c|c|c|c|c|}
\hline 1 & 2 & 3 & 4 & 5 & 6 \\
\hline Feed intake (g/bird/d) & 57.80 & $\begin{array}{l}55.23 \\
\end{array}$ & 58.70 & 2.00 & 0.48 \\
\hline FCR (g feed/g BW) & 1.47 & 1.36 & 1.43 & 0.03 & 0.16 \\
\hline Mortality (\%) & 0.83 & 0.00 & 0.00 & 0.47 & 0.39 \\
\hline \multicolumn{6}{|l|}{$21 \mathrm{~d}$} \\
\hline BW (g) & 796.36 & 841.00 & 818.84 & 20.38 & 0.32 \\
\hline BW gain (g/bird/d) & 59.32 & 62.74 & 60.31 & 1.91 & 0.45 \\
\hline Feed intake $(\mathrm{g} / \mathrm{bird} / \mathrm{d})$ & 90.83 & 89.21 & 89.21 & 2.34 & 0.64 \\
\hline FCR (g feed/g BW) & 1.51 & 1.39 & 1.48 & 0.04 & 0.14 \\
\hline Mortality (\%) & 0 & 0 & 0 & 0 & - \\
\hline \multicolumn{6}{|l|}{$28 \mathrm{~d}$} \\
\hline $\mathrm{BW}(\mathrm{g})$ & 1356.38 & 1451.95 & 1415.66 & 32.23 & 0.12 \\
\hline BW gain (g/bird/d) & 79.39 & 87.96 & 84.21 & 2.33 & 0.60 \\
\hline Feed intake $(\mathrm{g} / \mathrm{bird} / \mathrm{d})$ & 132.19 & 140.37 & 136.66 & 4.42 & 0.44 \\
\hline FCR (g feed/g BW) & 1.56 & 1.48 & 1.53 & 0.02 & 0.11 \\
\hline Mortality (\%) & 0 & 0 & 0 & 0 & - \\
\hline \multicolumn{6}{|l|}{$35 \mathrm{~d}$} \\
\hline BW (g) & 2052.24 & 2164.65 & 2093.20 & 34.82 & 0.10 \\
\hline BW gain (g/bird/d) & 99.14 & 101.10 & 95.06 & 2.07 & 0.14 \\
\hline Feed intake $(\mathrm{g} / \mathrm{bird} / \mathrm{d})$ & 181.51 & 189.41 & 185.21 & 2.48 & 0.11 \\
\hline FCR (g feed/g BW) & 1.66 & 1.60 & 1.65 & 0.01 & 0.14 \\
\hline Mortality (\%) & 0.00 & 0.00 & 0.83 & 0.47 & 0.39 \\
\hline \multicolumn{6}{|l|}{$42 \mathrm{~d}$} \\
\hline $\mathrm{BW}(\mathrm{g})$ & 2552.04 & 2660.37 & 2590.11 & 48.64 & 0.30 \\
\hline BW gain (g/bird/d) & 71.40 & 68.08 & 70.98 & 7.16 & 0.68 \\
\hline Feed intake (g/bird/d) & 174.23 & 180.80 & 179.48 & 4.35 & 0.59 \\
\hline FCR (g feed/g BW) & 1.81 & 1.78 & 1.83 & 0.01 & 0.13 \\
\hline Mortality (\%) & 0.00 & 0.83 & 0.00 & 0.47 & 0.39 \\
\hline \multicolumn{6}{|l|}{ Whole period ( 1 to $42 \mathrm{~d}$ ) } \\
\hline BW gain (g/bird/d) & 59.06 & 63.17 & 60.64 & 1.38 & 0.14 \\
\hline Feed intake (g/bird/d) & 106.53 & 112.63 & 110.35 & 2.23 & 0.18 \\
\hline FCR (g feed/g BW) & 1.80 & 1.78 & 1.81 & 0.013 & 0.20 \\
\hline Mortality (\%) & 2.5 & 0.83 & 1.66 & 0.1 & 0.52 \\
\hline
\end{tabular}

As shown in Table 2 and Table 3 secondary titers of SRBC, AI antibody, CBH, and also leukocyte numbers and total leukocyte were not affected by LED treatments and ICD light bulbs ( $\mathrm{P}>0.05$; Table 2). However, the lighting sources had a significant effect on primary $\mathrm{SRBC}$ and ND antibody titers $(\mathrm{P} \leq 0.05$; Table 2). Warm-white light treatment increased $(\mathrm{P} \leq 0.05)$ primary $\mathrm{SRBC}$ and ND antibody titers by approximately 47 and $24 \%$, respectively. 
Table 2. Effect of different color temperatures (kelvin) compared to incandescent (ICD) light bulbs on primary and secondary antibody of SRBC, Newcastle disease (ND) virus and avian influenza (AI)

virus antibody, and cutaneous basophilic hypersensitivity $(\mathrm{CBH})$ response of male broiler chicken performance

\begin{tabular}{l|l|l|l|l|l|l|l}
\hline \multirow{2}{*}{ Treatment } & \multirow{2}{*}{$\begin{array}{c}\text { Primary } \\
\text { SRBC }\end{array}$} & \multicolumn{3}{c|}{ Secondary } & \multirow{2}{*}{ ND } & \multirow{2}{*}{ AI } & \multirow{2}{*}{ CBH $(\mathrm{mm})$} \\
\cline { 3 - 5 } & SRD & SRB & IgG & IgM & & & \\
Warm-white & $0.95 \mathrm{ab}$ & 3.83 & 1.2 & 2.62 & $4.62 \mathrm{a}$ & 1.25 & 0.91 \\
Neutral-white & $1.20 \mathrm{a}$ & 3.58 & 1.41 & 0.16 & $5.00 \mathrm{a}$ & 2.00 & 0.85 \\
SEM & $0.63 \mathrm{~b}$ & 4.08 & 1.70 & 2.37 & $3.78 \mathrm{~b}$ & 2.00 & 0.84 \\
P-value & 0.139 & 0.490 & 0.335 & 0.361 & 0.310 & 0.564 & 0.116 \\
\hline
\end{tabular}

$\mathrm{a}, \mathrm{b}-$ means within each column without common letter are significantly different $(\mathrm{P} \leq 0.05)$.

Table 3. Effect of different color temperatures (kelvin) compared to incandescent (ICD) light bulbs on total and differential leukocyte count and heterophil to lymphocyte (H:L) ratio of male broiler chicken

(42 d of age)

\begin{tabular}{l|c|c|c|c|c|c}
\hline \multirow{2}{*}{ Treatment } & \multicolumn{7}{c}{ WBC } \\
\cline { 2 - 7 } & total leukocyte & heterophil & eosinophil & monocyte & lymphocyte & H:L ratio \\
\hline ICD & 14750 & 25.87 & 5.85 & 5.37 & 63.62 & 0.41 \\
Warm-white & 12375 & 27.35 & 5.62 & 7.00 & 59.50 & 0.43 \\
Neutral-white & 11060 & 23.75 & 3.37 & 8.00 & 64.87 & 0.38 \\
SEM & 1400 & 2.69 & 0.78 & 1.20 & 3.49 & 0.05 \\
P-value & 0.19 & 0.63 & 0.07 & 0.28 & 0.53 & 0.83 \\
\hline
\end{tabular}

\section{Discussion}

The three light treatments had no effect on performance of male broiler chicken during the whole period. However, marginally the body weight, and feed consumption were highest, and FCR was lowest in birds reared under warm-white light compared to other treatments. The results of this trial agree with those of Olanrewaju et al. (2015), who found that light source (LED vs. ICD) alone did not significantly influence broiler performance. However, in a study performed on broiler performance, it was shown that broilers from the cold-white $(6,065 \mathrm{~K})$ treatment were heavier than neutral-white $(4,100 \mathrm{~K})$ treatment on the day of slaughter, whereas feed intake was found to be similar for the two treatments (Riber, 2015). Also, Huth and Archer (2015) showed that LED treatments had increased feed conversion compared to compact fluorescent lamps (CFL) treatment. They suggested that this may be a result of decreased stress found in the LED treatments, which in turn, decreasing in "waste energy" may increase the amount of energy put towards muscle growth, thereby improving conversion of feed into muscle. During this study, the percentage of the mortality was not statistically different among the three light treatments. These results are in agreement with several studies in which light source (LED vs. ICD or LED vs. CFL) alone did not significantly influence the percentage of mortality (Huth and Archer, 2015; Olanrewaju et al., 2015). 
It has been well documented that different light colors and photoperiod regimens have an effective impact on immune responses in birds (Moore and Siopes, 2000; Blatchford et al., 2009) but the role of color temperatures of the LEDs on immune response of birds has not yet been well investigated. In this study, the highest primary SRBC and ND antibody titers were observed in warm-white light compared to other treatments. A study performed by Xie et al. (2008) showed that green and blue LEDs enhance cellular and humoral immune responses in broiler chickens. Also, Li et al. (2015) suggested that green LEDs illumination could improve the antioxidative capacity and secretion of melatonin to promote B lymphocyte proliferation of bursa of Fabricius in young broilers. Melatonin biosynthesis and secretion could be modulated by environmental light (Li et al., 2015). Moore and Siopes (2003) showed that melatonin stimulates the cellular and humoral immune responses in Japanese quail. In the present study, warm-white light might increase the melatonin secretion, thereby improving humoral immune responses.

In this study, the effect of the different color temperatures of the LEDs and ICDs on differential leukocyte numbers was not significant. In a study performed on broilers, it was shown that plasma corticosterone concentrations were not affected by treatments (LED vs. ICD) (Olanrewaju et al., 2015). A normal H:L ratio for hens is about 0.4 and it rises to 0.8 (due to the elevated blood corticosterol level) in birds under severe stress (Gross and Siegel, 1983). Considering poultry welfare, lack of significant impact of all treatments used in this study on H:L ratio at $42 \mathrm{~d}$ of age could be due to the ideal environmental conditions or an absence of physiological stress.

\section{Conclusion}

It is concluded that warm-white light is useful to provide optimum level of immunity and energy saving in commercial broiler houses.

\section{References}

Akhlaghi A., Zamiri M.J., Jafari Ahangari Y., Atashi H., Ansari Pirsaraei Z., D eld ar H., Eghbalian A.N., Akhlaghi A.A., Navidshad B., Yus sefi Kelarikol a e i K., Ha s h e m i S.R. (2013). Oral exposure of broiler breeder hens to extra thyroxine modulates early adaptive immune responses in progeny chicks. Poultry Sci., 92: 1040-1049.

B e s s e i W. (2006). Welfare of broilers: a review. World Poultry Sci. J., 62: 455-466.

B latchford R.A., Klas ing K.C., Shivaprasad H.L., Wakenell P.S., Archer G.S., Men ch J.A. (2009). The effect of light intensity on the behavior, eye and leg health, and immune function of broiler chickens. Poultry Sci., 88: 20-28.

Bobadilla-Mendez M.F., Rojas-Granados C.P., Andrade E.F., Retes P.L., Ferreira L.G., A lvarenga R.R., Rodriguez-Gil J.E., F as sani E.J., Zangeronim o M.G. (2016). Effect of different light sources on reproductive anatomy and physiology of Japanese quail (Coturnix coturnix japonica). Anim. Reprod. Sci., 168: 50-56.

C a o J., Li u W., Wang Z., X i e D., J i a L., Ch en Y. (2008). Green and blue monochromatic lights promote growth and development of broilers via stimulating testosterone secretion and myofiber growth. J. Appl. Poultry Res., 17: 211-218.

Gros s W.B., S i e gel H.S. (1983). Evaluation of the heterophil/lymphocyte ratio as a measure of stress in chickens. Avian Dis., 27: 972-979.

H a s s an M.R., Sultan a S., Ch o e H.S., Ry u K.S. (2014). A comparison of monochromatic and 
mixed LED light color on performance, bone mineral density, meat and blood properties, and immunity of broiler chicks. J. Poultry Sci., 51: 195-201.

H u th J.C., A r cher G.S. (2015). Comparison of two LED light bulbs to a dimmable CFL and their effects on broiler chicken growth, stress, and fear. Poultry Sci., 94: 2027-2036.

L e ven ick C.K., Leighton A.T. Jr. (1988). Effects of photoperiod and filtered light on growth, reproduction, and mating behavior of turkeys. 1. Growth performance of two lines of males and females. Poultry Sci., 67: 1505-1513.

Li J., Ca o J., Wang Z., Dong Y., Chen Y. (2015). Melatonin plays a critical role in inducing B lymphocyte proliferation of the bursa of Fabricius in broilers via monochromatic lights. J. Photoch. Photobiol. B, Biology, 142: 29-34.

M o ore C.B., S i opes T.D. (2000). Effects of lighting conditions and melatonin supplementation on the cellular and humoral immune responses in Japanese quail Coturnix coturnix japonica. Gen. Comp. Endocr., 119: 95-104.

M o or e C.B., S i o p e s T.D. (2003). Melatonin enhances cellular and humoral immune responses in the Japanese quail (Coturnix coturnix japonica) via an opiatergic mechanism. Gen. Comp. Endocr., 131: 258-263.

O 1 a n r ew a ju H.A., Purs w e 11 J.L., M a s 1 in W.R., Colli e r S.D., B rant o n S.L. (2015). Effects of color temperatures (kelvin) of LED bulbs on growth performance, carcass characteristics, and ocular development indices of broilers grown to heavy weights. Poultry Sci., 94: 338-344.

R iber A.B. (2015). Effects of color of light on preferences, performance, and welfare in broilers. Poultry Sci., 94: 1767-1775.

Rozenboim I., Biran I., Chaiseha Y., Yahav S., Rosenstrauch A., Sklan D., Hale v y O. (2004). The effect of a green and blue monochromatic light combination on broiler growth and development. Poultry Sci., 83: 842-845.

S e o H.-S., Kang M., Yoon R.-H., Roh J.-H., Wei B., Ryu K.S., Cha S.-Y., Jang H.-K. (2015). Effects of various LED light colors on growth and immune response in broilers. J. Poultry Sci., 53: 76-81.

S k o glund W.C., P a lmer D.H. (1962). Light intensity studies with broilers. Poultry Sci., 41: 1839-1842.

Van Der Zijpp A.J., Leenstra F.R. (1980). Genetic analysis of the humoral immune response of White Leghorn chicks. Poultry Sci., 59: 1363-1369.

Xi e D., Wang Z.X., D ong Y.L., C a o J., Wang J.F., Chen J.L., Chen Y.X. (2008). Effects of monochromatic light on immune response of broilers. Poultry Sci., 87: 1535-1539.

Xie D., Li J., Wang Z.X., C a o J., Li T.T., Chen J.L., Ch en Y.X. (2011). Effects of monochromatic light on mucosal mechanical and immunological barriers in the small intestine of broilers. Poultry Sci., 90: 2697-2704.

Zhandi M., Sharideh H., Zaghari M., Akhlaghi A. (2016). Dietary zinc oxide and 6-phytase effects on fertility rate in old broiler breeder hens. J. Agric. Sci. Technol., 18: 327-336.

Received: 3 V 2016

Accepted: 27 X 2016 